\title{
Knowledge and practice of injection safety among healthcare workers in a Nigerian secondary healthcare facility
}

\author{
Salisu Abubakar', Ruqayya Hamza Usman¹, Abdulrashid Idris', Ibrahim Muhammad², \\ Mahfuz Muhammad Haddad', Chioma Judith Mba'
}

${ }^{1}$ Department of Nursing Science, Bayero University Kano, Nigeria

${ }^{2}$ Jigawa State College of Nursing and Midwifery, Birnin Kudu, Nigeria

doi: 10.3396/IJIC.v15i1.004.19

\begin{abstract}
Injection safety is important in today's healthcare delivery particularly in settings with a high burden of blood-borne viruses. A safe injection protects the patient, the healthcare worker and the community from avoidable infections. In Nigeria, the national policy on injection safety and healthcare waste management were developed in 2007. The development of the policy was followed by series of training on safe injection and behavioural change. Despite this, burden of unsafe injections was reported in many parts of the country. This study assessed the level of knowledge and practice of injection safety among healthcare workers in a secondary healthcare facility in north-western Nigeria. The study targeted all the healthcare workers employed in the hospital. A self-administered questionnaire was distributed to all the available healthcare workers.
\end{abstract}

A total of 80/88 questionnaires were returned and analysed. Majority of the respondents were males in their early career who were within the age range of $31-40$ years. The results showed that $88.7 \%$ of the healthcare workers correctly described injection safety as defined by the WHO. However, only $18.7 \%$ had good knowledge of risks associated with unsafe injection and $40.0 \%$ with diseases that can potentially be transmitted. In addition, only $25.0 \%$ reported safe injection practices. Reuse of syringe was reported by $37.5 \%$ of the respondents and $88.7 \%$ recap used needles. Majority of the healthcare workers reported a previous history of needlestick injury, which was not associated with their professional cadre.

Despite injection safety training, inadequate knowledge with poor injection practice was found among the surveyed healthcare workers. The reuse of syringes and needles underscores the need for adequate and safe injection commodities at all levels of healthcare delivery. This suggests that the training of healthcare workers was ineffective at eradicating unsafe injection practice.

Keywords: healthcare workers, injections, safety, knowledge, Nigeria

\section{Corresponding Author}

Salisu Abubakar

Department of Nursing Science, Bayero University Kano, Nigeria

Email: salisrn@yahoo.com 


\section{Introduction}

The safety of injection is an important issue in today's healthcare where injectable medications and vaccines are commonly used. Coupled with this is the high burden of blood-borne pathogens with potential of transmission through accidental exposure to contaminated needles and syringes. ${ }^{1}$ Globally, the World Health Organization (WHO) estimated that billions of injections are administered every year within healthcare settings. ${ }^{2}$ These injections according to the WHO are commonly used for curative purposes, most of which are unnecessary and avoidable. Inappropriate injections can lead to avoidable harm particularly in developing countries where safety resources and practices cannot always be guaranteed. ${ }^{3}$ A recent estimate of the burden of blood-borne infections due to unsafe injection practices revealed that up to $46 \%$ of hepatitis B, 38\% of hepatitis $C$ and $12 \%$ of human immunodeficiency virus (HIV) infections are associated with unsafe injections. ${ }^{4}$ Furthermore, unsafe injection practices can fuel the transmission of other emerging and reemerging infectious diseases such as the Ebola virus disease. ${ }^{5}$ Modelling using the fraction of unsafe injection-associated bloodborne viral infections estimated a burden of 9.18 million preventable disability-adjusted life years from 2000 to $2030 .^{6}$

According to the WHO's Safe Injection Global Network (SIGN), a safe injection is one that does not harm the recipient, does not expose the provider (HCWs) to any avoidable risks and does not result in waste that is dangerous to the community. ${ }^{7}$ Hence, safe injection practice involves the administration of rational injection by a qualified and well-trained person using a sterile device, right technique, proper disposal and management of the wastes generated. The SIGN was launched by the $\mathrm{WHO}$ as an alliance of global stakeholders to support and ensure the safe, logical and proper use of injections worldwide. ${ }^{7}$ One of the strategies to achieve the goal of this coalition as highlighted by SIGN is the behaviour change of healthcare workers. The healthcare workers are those individuals who deliver health services such as injection to the sick either directly as nurses and physicians or indirectly as environmental health, laboratory and other supportive staff including waste handlers. ${ }^{8}$ It is believed that behaviour change among the injection providers will improve the healthcare workers' and patient safety by preventing the reuse of injection equipment, reducing unnecessary injections, prevention of needlestick injuries and enhancement of community safety via safe sharps and other waste management. ${ }^{9}$

In Nigeria, a national policy on injection safety and healthcare waste management was formulated in 2007 to address the problem of unsafe injection practices. ${ }^{10}$ The policy supported by the United States Agency for International Development (USAID) under the President's Emergency Plan For AIDS Relief (PEPFAR) project included training programmes for healthcare workers on injection safety in the context of infection prevention and control and behaviour change. ${ }^{11}$

Despite the existence of the policy document and training of the healthcare providers, high burden of injections and unsafe practices was reported in parts of Nigeria. ${ }^{12}$ In addition, an array of studies found that around half of the healthcare workers had poor or low level of injection safety knowledge. ${ }^{13,14}$ Equally, a wide gap was reported between the injection safety knowledge and practice with many injection providers engaging in unsafe injection practices such as recapping of used needles and syringes..$^{15,16}$

Currently, little is known about the knowledge and practice of injection safety among healthcare workers in sub-urban hospitals of north-western Nigeria. Consequently, the aim of this study was to assess the level of knowledge and practice of injection safety among the healthcare workers at Birnin kudu General Hospital in north-western Nigeria. It is hoped that findings will help inform professionals, patient groups and policymakers.

\section{Methods}

The study was conducted in Birnin kudu General Hospital, a secondary healthcare facility in Jigawa State, north-western Nigeria. Birnin kudu is a local government that hosts most of Jigawa States' healthcare training schools. Thus, students are regularly posted to the general hospital for clinical experience as part of their training. The hospital has 12 units which include medical, surgical, paediatrics obstetrics and gynaecology, and serves as a referral centre for 37 
primary health centres in the local government. The study hospital had a total number of 98 healthcare workers which included nurses, doctors, laboratory technologists, dental technicians, environmental health and community health extension workers (CHEWs). However, ten were not reached for they were either on holiday or off duty and 88 agreed to participate in the study.

The study population included all the healthcare workers employed within the hospital. In view of the small population, all the healthcare workers of the hospital were considered so as to get a sufficient sample size and avoid potential statistical error. ${ }^{17}$ The study targeted to recruit all the 88 healthcare workers. Thus, all the hospital units were visited during all the shift hours and staff not on duty were reached by their unit managers or team lead.

The tool used for the data collection was adapted from $\mathrm{WHO}$ revised tool $\mathrm{C}$ for assessment of safe injection practices among injection providers and phlebotomists. ${ }^{18}$ The adapted tool was designed in a form of a structured self-administered questionnaire to elicit responses that will answer the research questions. The tool was assessed for clarity, completeness, face and content validity by the investigators and subsequently by an infection control specialist. The questionnaire included demographic details including age, gender, tribe, marital status, professional cadre and years of experience. The main aspect of the questionnaire comprised of questions related to knowledge of injection safety, formal training, national policy, risks associated with unsafe injection and diseases that can potentially be transmitted. The last section of the questionnaire consisted of practices that ensure safe injection, needle recapping, needlestick injury and access to prophylaxis following accidental exposure and reasons for not reporting an exposure. Respondents were asked to choose the answer they believe is correct. In assessing the knowledge and practice score, $0-59 \%$ was considered poor, $60-69 \%$ fair and $\geq 70 \%$ was considered good.

The questionnaires were distributed to all the healthcare workers directly or through their clinical supervisors. A total of 88 questionnaires were distributed and the respondents were given time to fill and return the questionnaires within two days to the study investigators.

Data were analysed using descriptive and inferential statistics, the Statistical Package for Social Sciences (SPSS) Version 23 (IBM, Armonk NY) was used. The relationship between variables was determined using chi-square test with statistical significance set at a $p$-value $=0.05$.

Ethical clearance to conduct the study was granted by the Research and Ethics Committee of the College of Health Sciences, Bayero University Kano, and the management of the hospital approved the study. All the study participants were required to read, understand and sign a consent form prior to participation. Additionally, participation in the study was voluntary and the healthcare workers had the right to decline participation.

\section{Results}

Out of the 88 healthcare workers who agreed to participate in the study and given the questionnaires, 80 filled and returned their questionnaires indicating a response rate of $90.9 \%$. Majority of the respondents $42(52.5 \%)$ were within the age range of 31-40 years followed by $36(45.0 \%)$ who were within the age group of $21-30$ years and the least $2(2.5 \%)$ were between 41-50 years old. Seventy (87.5\%) of the respondents had $1-10$ years' clinical experience, $9(11.3 \%)$ had 11 20 years, only 1 (1.3\%) had over 20 years' experience. Respondents were predominantly male $50(62.5 \%)$ and the majority $65(81.3 \%)$ were locals (Hausa). Furthermore, over half of the respondents $46(57.5 \%)$ were nurses, followed by the CHEWs $(12,15 \%)$, and doctors formed only $3.8 \%$ of the study population. Details of the respondent's demographic characteristics are shown in Table I.

Only $10(12.5 \%)$ of the respondents reported not attending any formal training on injection safety and healthcare waste management. Healthcare workers were fully aware of injection safety as the majority $(71$, $88.7 \%$ ) correctly described injection safety as defined by the WHO while the remaining $9(11.3 \%)$ described injection safety as either using a new syringe and needle only or the act of safe disposal of used syringe 
and needle. Though the majority $(59,78.7 \%)$ of the respondents had a fair knowledge of risks associated with unsafe injections, only $15(18.7 \%)$ were found to have good knowledge. Accordingly, over half 42 $(52.5 \%)$ had a fair knowledge of the diseases that can be transmitted through unsafe injections. Forty percent (32) of the healthcare workers had good knowledge of the diseases that can potentially be transmitted through unsafe injection practice, while $4(5.0 \%)$ were not aware of such infections. Seventy-five respondents $(93.7 \%)$ were aware of the risk associated with unsafe recapping of a used needle (Table II). A chisquare test showed a significant relationship between the healthcare workers' years of experience and knowledge of injection safety ( $p=0.001$ ) (Table III).

On the practice of injection safety among the surveyed healthcare workers, only 11 (13.7\%) reported practising hand hygiene before and or after an injection. More so, $70(87.5 \%)$ reported poor disposal of used syringes and needles and $71(88.7 \%)$ recap used needles prior disposal. Additionally, 30 (37.5\%) reported not using a new syringe and needle for injection. There was no significant association between category of the healthcare workers and practice of infection safety $(p=0.06)$.

Only a few respondents $25(31.2 \%)$ reported not experiencing a needlestick injury while on their duty (Table IV). The rate of the needlestick injury was higher among doctors $3 / 3$ (100\%) followed by CHEWs $11 / 12$ $(91.6 \%)$, nurses $31 / 46(64.4 \%)$ and then laboratory staff $4 / 7$ (57.1\%). The lowest incidence of needlestick injury was among environmental/public health and dental technicians 6/12 (50.0\%). However, there was no significant relationship between the needlestick injuries and cadre of the healthcare workers $(p=0.08)$. However, a significant association was found between

Table I. Socio-demographic characteristics of the respondents

\begin{tabular}{|c|c|c|c|}
\hline \multicolumn{2}{|c|}{ Variable } & \multirow{2}{*}{$\begin{array}{c}\text { Frequency } \\
36\end{array}$} & \multirow{2}{*}{$\begin{array}{c}\text { Percent } \\
45.0\end{array}$} \\
\hline \multirow{3}{*}{ Age } & 21-30years & & \\
\hline & 31-40years & 42 & 52.5 \\
\hline & 41-50years & 2 & 2.5 \\
\hline \multirow{2}{*}{ Gender } & Male & 50 & 62.5 \\
\hline & Female & 30 & 37.5 \\
\hline \multirow{4}{*}{ Tribe } & Hausa & 65 & 81.3 \\
\hline & Fulani & 10 & 12.5 \\
\hline & Yoruba & 3 & 3.8 \\
\hline & Igbo & 2 & 2.5 \\
\hline \multirow{2}{*}{ Marital status } & Married & 53 & 66.3 \\
\hline & Single & 27 & 33.8 \\
\hline \multirow{5}{*}{ Staff cadre } & Nurses & 46 & 57.5 \\
\hline & Doctors & 3 & 3.8 \\
\hline & CHEWs & 12 & 15.0 \\
\hline & Lab. Staff & 7 & 8.8 \\
\hline & Others & 12 & 15.0 \\
\hline \multirow{3}{*}{ Years of experience } & $1-10$ & 70 & 87.5 \\
\hline & $11-20$ & 9 & 11.25 \\
\hline & Above 20 & 1 & 1.25 \\
\hline
\end{tabular}


Table II. Respondents' knowledge of safe injection safety

\begin{tabular}{lcc} 
Variable & Frequency & Percent \\
\hline WHO definition of a safe injection & & \\
\hline Correct & 71 & 88.75 \\
Incorrect & 9 & 11.25 \\
Risks associated with unsafe injection & & \\
\hline Good & 15 & 18.75 \\
Fair & 59 & 73.75 \\
Poor & 6 & 7.50 \\
Diseases that can be transmitted through unsafe injection & \\
\hline Good & 32 & 40.00 \\
Fair & 42 & 52.50 \\
Poor & 6 & 7.50
\end{tabular}

Table III. Respondents' knowledge and years of clinical experience

\begin{tabular}{lccc} 
Knowledge of Injection Safety & Years of experience & Frequency & Statistics \\
\hline \multirow{3}{*}{ Good } & $1-10$ years & 61 & \\
\cline { 1 - 2 } & $11-20$ years & 4 & X2 $=13.932$ \\
Inadequate & $>20$ years & 0 & $\mathrm{df}=2$ \\
& $1-10$ years & 9 & $\mathrm{p}=0.001$ \\
& $11-20$ years & 5 &
\end{tabular}

the respondents' years of experience and needlestick injury. Those with least years of experience were more likely to suffer injury from used needle $(p=0.009)$.

The majority $(48 / 55,87.3 \%)$ of the healthcare workers who had needlestick injuries reported their injuries and $44(91.7 \%)$ of those who reported the accidental exposures were advised on blood tests and postexposure prophylaxis (PEP). The belief that patient was not known to be HIV positive, the needle was not contaminated, and being too busy were reasons given by the healthcare workers who failed to report or take any action following their needlestick injuries.

\section{Discussion}

Good knowledge and practice of injection safety are important particularly in developing sub-Saharan
African countries where the pool of people living with blood-borne viruses is high. ${ }^{19}$ The high prevalence of blood-borne viruses places the healthcare workers at risk of exposure to contaminated sharps. Equally, the community may not be safe when used injection equipment is not segregated and properly disposed of. In Nigeria, there were a lot of efforts to promote the safety of the injection recipient, the healthcare workers and the community. ${ }^{12}$ An overwhelming majority of the current study population attended a formal training on injection safety as reported in a previous study. ${ }^{20}$

This study revealed that many of the healthcare workforce were in their early careers within the range of 1 - 10 years. Despite good knowledge of a safe injection as defined by the $\mathrm{WHO}$, most of the 
Table IV. Respondents' self-reported injection safety practices

\begin{tabular}{lccc} 
Variable & Yes & No & \multirow{2}{*}{ Statistics } \\
\cline { 1 - 2 } & \multicolumn{1}{c}{ Frequency (percent) } & \\
\cline { 1 - 2 } Hand hygiene & $11(13.7)$ & $69(86.3)$ & \\
Use of new syringe and needle & $50(62.5)$ & $30(37.5)$ & \\
No recapping of used needle & $9(11.3)$ & $71(88.7)$ & $\mathrm{df}=12$ \\
Proper disposal of sharps & $10(12.5)$ & $70(87.5)$ & $\mathrm{p}=0.062$ \\
Needlestick injury & & & \\
\hline Nurses & $31(64.4)$ & $15(35.6)$ & \\
Doctors & $3(100)$ & $0(0)$ & $\mathrm{X} 2=6.739$ \\
CHEWs & $11(91.6)$ & $1(8.4)$ & $\mathrm{df}=4$ \\
Lab. Staff & $4(57.1)$ & $3(0)$ & $\mathrm{p}=0.08$ \\
Others & $6(50)$ & $6(50)$ &
\end{tabular}

study participants had only a fair knowledge of the risks associated with unsafe injection as well as the diseases that can potentially be transmitted through unsafe injection practices. Only about $19 \%$ of the respondents had good knowledge of the risks. In addition, $60 \%$ of the healthcare workers could not identify HIV and the hepatotropic viruses as bloodborne pathogens with potential of transmission through unsafe injection practice. It is alarming that the healthcare workers cannot demonstrate adequate knowledge of these diseases, in an era when Africa is experiencing outbreak of haemorrhagic diseases that can equally be transmitted through unsafe injections. ${ }^{21}$ The findings of this study contradict the study of Onyemocho and colleagues who found knowledge of injection safety among prison healthcare workers to be adequate. ${ }^{14}$ However, poor knowledge of injection safety was earlier reported in the southern region of Nigeria. ${ }^{22}$ The current study respondents' knowledge of injection safety was better when compared with the findings from southwestern Nigerian hospitals where the respondents' knowledge of injection safety was below $22 \% .^{23}$ Similarly, a recent study, reported over $75 \%$ of a tertiary hospital healthcare workers were not aware of good injection safety practices. ${ }^{24}$

The study also found that the healthcare workers do not comply with good injection safety practices. Most $(60 \%)$ of the healthcare workers reported reusing needles, not disposing of sharps in a designated sharps container, recapping used needles and failing to observe hand hygiene before and / or after an injection (Table IV). These practices put the healthcare workers, patients and the community at risk of infections. The most disturbing unsafe practice was the reuse of needles which is an easy way of spreading infections such as HIV or hepatitis. ${ }^{25,26}$ The high incidence of needlestick injuries among the healthcare workers was probably due to their poor injection safety practices. Previous studies on injection safety reported a high incidence of needlestick injuries among Nigerian healthcare workers. ${ }^{22,23}$ The rate of needlestick injury being higher among doctors followed by nurses supported the findings of over a decade review of occupational exposure and post-exposure prophylaxis (PEP). ${ }^{27}$ The practice of needle recapping was equally observed and reported among Ethiopian healthcare workers. ${ }^{28}$

Accidental exposure of healthcare workers to contaminated needles could expose them to the risk of infection such as HIV and effective PEP can eliminate the risk. ${ }^{29}$ In this study, over $87 \%$ of the exposed healthcare workers reported their injuries and almost $92 \%$ where offered advice on testing and prophylaxis. This proved that the healthcare workers were aware of PEP and its potential advantage in halting occupational infection transmission. These findings are in contrast with previous studies where poor reporting of needlestick injuries among some Nigerian healthcare workers were reported. ${ }^{16,23}$ 
The lack of good knowledge of the risks associated with, and the infections that can be transmitted through unsafe injections, supports the finding of a previous study where doctors and nurses were reported to have poor knowledge of blood-borne infection transmission following occupational exposure. ${ }^{30}$

\section{Limitations}

This study surveyed all the (consented) healthcare workers in Birnin kudu General Hospital who are directly or indirect involved in injection safety. The study participants were given up to 2 days to fill and return questionnaires given to them. This may introduce some information bias as may have referred to other sources for answers. However, this may not be the case considering the low level of knowledge demonstrated and poor self-reported practices. In addition, observation of practice might be a better way of establishing the level of the healthcare workers' behaviours towards safe injection. However, due to some constraints, the study data were collected using self-administered questionnaires with no observation of injection practice. Thus, the study findings were based on healthcare workers' self-reported knowledge and practice of injection safety. This will give a platform to carry out another study with incorporation of the lessons learnt from this study. Another limitation is that this study did not check supplies of injection safety commodities or find out the how and why the healthcare workers re-use needle and syringes. Equally, the study did not assess re-training and supportive supervision, for these make the difference as far injection safety practice.

\section{Conclusions}

Despite national efforts to inform the Nigerian healthcare workers on the importance and risks associated with unsafe injections, this study established that the healthcare workers do not possess a good knowledge of the concept of injection safety. Equally, there is a wide gap between the fair knowledge and the practice of injection safety among the healthcare workers. The study further established that re-use of syringe and needle is still a problem in Nigeria. This highlights the need for training and re-training of the healthcare workers on the general concept of injection safety including healthcare waste management. It further underscores the need for government to ensure the provision of safe injection commodities and regular supportive supervision at all levels of healthcare delivery.

\section{References}

1. Costa MD, Rapparini C, Schmaltz CAS, et al. Danger in the streets: exposures to bloodborne pathogens after community sharp injuries in Rio de Janeiro, Brazil. Brazilian J Infect Dis 2017; 21(3): 306-311. https://doi.org/10.1016/j. bjid.2017.03.003

2. WHO. WHO calls for worldwide use of "smart" syringes. World Health Organization; 2015. Available from: http://www. who.int/mediacentre/news/releases/2015/injection-safety/en/

3. Gyawali S, Sharma D, Rathore DS, Shankar PR, Kc VK, Jha N. Knowledge and Practice on Injection Safety among Primary Health Care Workers in Kaski District, Western Nepal. Malaysian J Med Sci 2016; 23(1): 44-55.

4. Reid S. Estimating the burden of disease from unsafe injections in India: A cost-benefit assessment of the auto-disable syringe in a country with low blood-borne virus prevalence. Indian / Community Med 2012; 37(2): 89-94. https://doi. org/10.4103/0970-0218.96093

5. CDC. For General Healthcare Settings in West Africa: Preventing Injury from Injections and Sharps. Centers for Disease Control and Prevention. 2015. Available from: https:// www.cdc.gov/vhf/ebola/hcp/international/safe-injectionpractices.html

6. Dziekan G, Chisholm D, Johns B, Rovira J, Hutin YJF. The cost-effectiveness of policies for the safe and appropriate use of injection in healthcare settings. Bull World Health Organ 2003; 81(4): 277-285.

7. WHO. Safe Injection Global Network (SIGN) Annual Meeting Report. 2002. Available from: http://apps.who.int/ medicinedocs/documents/s15266e/s15266e.pdf

8. Joseph B, Joseph M. The health of the healthcare workers. Indian J Occup Environ Med 2016; 20(2): 71-72. https://doi. org/10.4103/0019-5278.197518

9. Gyawali S, Rathore DS, Shankar PR, Kumar KV. Strategies and challenges for safe injection practice in developing countries. J Pharmacol Pharmacother 2013; 4(1): 8-12. https://doi. org/10.4103/0976-500X.107634

10. MoH. Ministry of Health: National policy on injection safety and healthcare waste management. Abuja, Nigeria; 2007 p. 30 .

11. AIDS Support and Technical Assistance Resources. Assessment of injection safety in selected local government areas in five states in Nigeria: 2011 Baseline Report. 2012. Available from: https://aidsfree.usaid.gov/sites/default/files/assessment_of_ injection_safety_in_nigeria_baseline.pdf

12. Sowande AO, Jibowu OL, Amaefule KE, Pearson J, Iyortim I. Safe Injection in the Context of IPC - Changing Landscape in Nigeria. Int / Infect Control 2014; 10(1): 1-4. https://doi.org/ 10.3396/IJIC.v10i1.005.14

13. Gadzama G, Bawa S, Ajinoma Z, Saidu M, Umar A. Injection safety practice in a main referral hospital in northeastern Nigeria. Niger / Clin Pract 2013; 17(2). https://doi. org/10.4103/1119-3077.127420

14. Onyemocho A, Anekoson IJ, Pius EO. Knowledge and practice of injection safety among workers of Nigerian prison service 
health facilities in Kaduna State. Am I Public Heal Res 2013; 1(7): 171-176. Available from: http://pubs.sciepub.com/ ajphr/1/7/5/index.html

15. Bolarinwa Akeem O, Salaudeen Ganiyu A, Aderibigbe Adedeji S, Musa Ibraheem O, Akande Makanjuola T, Bamidele Olusegun J. Injection safety practices among primary health care workers in Ilorin, kwara state of Nigeria. Heal Sci J 2012; 6(3): 496-509.

16. Enwere OO, Diwe KC. Knowledge, perception and practice of injection safety and healthcare waste management among teaching hospital staff in south east Nigeria: an intervention study. Pan Afr Med J 2014; 17: 218. https://doi.org/10.11604/ pamj.2014.17.218.3084

17. Wilson Von Voorhis CR, Morgan BL. Understanding power and rules of thumb for determining sample sizes. Tutor Quant Methods Psychol 2007; 3(2): 43-50. https://doi.org/10.20982/ tqmp.03.2.p043

18. WHO. Revised Injection Safety Assessment Tool (Tool C - Revised): Tool for the assessment of injection safety and the safety of phlebotomy, Lancet Procedures, Intravenous Injections and Infusions. World Health Organization 2008. Available from: http://www.who.int/infection-prevention/ tools/injections/ToolC-revised.pdf

19. Khyatti M, Trimbitas RD, Zouheir Y, Benani A, El Messaoudi MD, Hemminki K. Infectious diseases in North Africa and North African immigrants to Europe. Eur J Public Health 2014; 24(Suppl 1): 47-56. https://doi.org/10.1093/eurpub/cku109

20. Ijachi OO, Audu O, Araoye M. Knowledge, attitude and practice of injection safety among Benue State University Teaching Hospital healthcare professionals. I Community Med Prim Heal Care 2016; 28(2): 26-33. Available from: https://www. ajol.info/index.php/jcmphc/article/viewFile/154691/144274

21. CDC. Review of human-to-human transmission of Ebola virus. Centers for Disease Control and Prevention 2015. p. 4330-4341. Available from: https://www.cdc.gov/vhf/ebola/ transmission/human-transmission.html
22. Omorogbe $\mathrm{V}$, Omuemu $\mathrm{V}$, Isara A. Injection safety practices among nursing staff of mission hospitals in Benin City, Nigeria. Ann Afr Med 2012; 11(1): 36. https://doi.org/10.4103/15963519.91020

23. Adejumo PO, Dada FA. A comparative study on knowledge, attitude, and practice of injection safety among nurses in two hospitals in Ibadan, Nigeria. Int I Infect Control 2013; 9(1): 4-9. https://doi.org/10.3396/ijic.v9i1.004.13

24. Kulkarni RS, Giri PA, Gangwal PR. Injection safety: knowledge and practices among nursing personnel in tertiary care teaching hospital of Marathwada Region of India. Arch Community Med Public Health 2016; 2(1): 18-21. https://doi. org/10.17352/2455-5479.000011

25. Sikora C, Chandran AU, Joffe AM, Johnson D, Johnson M. Population risk of syringe reuse: estimating the probability of transmitting bloodborne disease. Infect Control Hosp Epidemiol 2010; 31(7): 748-754. https://doi.org/10.1086/653200

26. Pépin J, Chakra CNA, Pépin E, Nault V, Valiquette L. Evolution of the global burden of viral infections from unsafe medical injections, 2000-2010. PLoS One 2014; 9(6): e99677. https:// doi.org/10.1371/journal.pone.0099677

27. Abubakar S, Iliyasu G, Dayyab FM, et al. Post-exposure prophylaxis following occupational exposure to HIV and hepatitis B: an analysis of a 12-year record in a Nigerian tertiary hospital. I Infect Prev 2017; 175717741774673. https://doi.org/10.1177/1757177417746733

28. Gulilat K, Tiruneh G. Assessment of knowledge, attitude and practice of health care workers on infection prevention in health institution Bahir Dar city administration. Sci J Public Health 2014; 2(5): 384-393. https://doi.org/10.11648/j. sjph.20140205.13

29. WHO. Post-exposure prophylaxis to prevent HIV infection. World Health Organization; 2014. Available from: http:// www.who.int/hiv/topics/prophylaxis/info/en/

30. Iliyasu G, Dayyab F, Habib Z, et al. Knowledge and practices of infection control among healthcare workers in a Tertiary Referral Center in North-Western Nigeria. Ann Afr Med 2016; 15(1): 34. https://doi.org/10.4103/1596-3519.161724 